\title{
Ectopic expression of citrus UDP-GLUCOSYL TRANSFERASE gene enhances anthocyanin and proanthocyanidins contents and confers high light tolerance in Arabidopsis
}

\author{
Muhammad Junaid Rao, Yuantao Xu, Yue Huang, Xiaomei Tang, Xiuxin Deng and Qiang Xu* (D)
}

\begin{abstract}
Background: Citrus fruits are consumed freshly or as juice to directly provide various dietary flavonoids to humans. Diverse metabolites are present among Citrus genera, and many flavonoids biosynthetic genes were induced after abiotic stresses. To better understand the underlying mechanism, we designed experiments to overexpress a UDPGLUCOSYL TRANSFERASE gene from sweet orange (Citrus sinensis) to evaluate its possible function in metabolism and response to stress.

Results: Our results demonstrated that overexpression of CS-UGT78D3 resulted in high accumulation of proanthocyanidins in the seed coat and a dark brown color to transgenic Arabidopsis seeds. In addition, the total contents of flavonoid and anthocyanin were significantly enhanced in the leaves of overexpressed lines. Gene expression analyses indicated that many flavonoid (flavonol) and anthocyanin genes were up-regulated by 4-15 folds in transgenic Arabidopsis. Moreover, after 14 days of high light stress, the transgenic Arabidopsis lines showed strong antioxidant activity and higher total contents of anthocyanins and flavonoids in leaves compared with the wild type.

Conclusion: Our study concluded that the citrus Cs-UGT78D3 gene contributes to proanthocyanidins accumulation in seed coats and confers tolerance to high light stress by accumulating the total anthocyanin and flavonoid contents with better antioxidant potential (due to photoprotective activity of anthocyanin) in the transgenic Arabidopsis.
\end{abstract}

Keywords: Citrus, proanthocyanidins, total flavonoid contents, anthocyanin, photoprotective, Arabidopsis

\section{Background}

Citrus is mostly cultivated fruit crops worldwide and its fruits are consumed freshly or as juice (oranges and mandarins). The fruit provide abundant amount of vitamins, carotenoids, folate, dietary fibers, flavonoids [1], proanthocyanidins (PAs) and anthocyanins [2] and is becomes a direct source of dietary metabolites. Flavonoids are further divided into various subclasses such as flavanones, isoflavones, flavonols, flavones, flavanols and anthocyanins [3] which play important role in the protection and defense of

\footnotetext{
* Correspondence: xuqiang@mail.hzau.edu.cn

Key Laboratory of Horticultural Plant Biology (Ministry of Education), Key Laboratory of Biology and Genetic Improvement of Horticultural Crops (Ministry of Agriculture), Huazhong Agricultural University, Wuhan, Hubei 430,070, People's Republic of China
}

plants against biotic and abiotic factors $[4,5]$; in addition flavonoids also reduces the risk of many chronic diseases such as cancer in humans $[6,7]$.

Proanthocyanidins (condensed tannins) are oligomeric or polymeric flavonoid compounds [8]. PAs are widely distributed in whole plant kingdom but mostly they are accumulated in seeds and fruits [8]. PAs functionally protects plants from abiotic (UV radiation) and biotic (fungus and insect pests) factors [9] and also beneficial for humans (anticancer, anti-inflammatory activity and protect skin from sun damage) $[8,10]$. Anthocyanins are also subclass of flavonoids which is involved in pollen dispersal, fruits and flower colors, plant defense, and development [11]. The chemical structures of anthocyanins and flavonols are 
supposed to have strong antioxidant properties which are vital for scavenging of reactive oxygen species (ROS) [11]. These compounds protect plants from various environmental factors such as intense light, cold, UV damage, high temperature and biotic stresses [12]. Recently, it was reported that several flavonoid pathway genes (o-methyl transferase, flavonol synthase, flavonoid 3 '-monooxygenase, leucoanthocyanidin dioxygenase etc.) that belongs to flavone, flavonol and anthocyanin biosynthesis pathways were significantly up-regulated in citrus after Huanglongbing invasion [13-16]. Flavonoid compounds are famous due to antimicrobial, photoprotective and have resilient antioxidant properties to scavenging the ROS abiotic $[17,18]$ and biotic stress [19]. Whenever citrus plants are exposed to different abiotic and biotic stresses then they stimulate its secondary defense machinery (such as anthocyanins and flavonoids) to protect itself from challenging environmental conditions.

In citrus, many studies have been reported at genetic [20] and anatomical level to understand the tolerance and defense mechanism [21, 22]. Many researches have been reported that citrus plant accumulates secondary metabolites (flavonoids, anthocyanin, etc.) after abiotic stress [23] or biotic stress [19]. However, the key gene to bridge the secondary metabolite and defense response are less known [7]. The Citrus genera consist of about 162 species [24]; of them sweet oranges, mandarins, pummelos, lemons and grapefruits are the famous cultivated Citrus species worldwide. Varied degrees of anthocyanin contents are present among Citrus genera; some wild citrus species possess high level of anthocyanin in fruit, flower and tender leaves [2].

In plants, UDP-glycosyl transferases (UGTs) is a large gene family such as the model plant Arabidopsis thaliana contains a total number of 120 UGTs [25]; that is involved in the secondary metabolites biosynthesis, conjugating hormones, abiotic and biotic stress toxins and also influence on plant cellular homeostasis [25]. In addition, some UGTs gene such as UGT74B1 enzyme functions in glucosinolate biosynthesis in Arabidopsis [26]. The UGTs, especially GT1 enzyme, is involved in the regulation of anthocyanins and precursors of wide-range of pigmented polymers that gives attractive color to fruits and flowers of red grapes (Vitis vinifera) [27]. In addition the GT1 gene from Cyclocarya paliurus (Batalin) Iljinsk (a medicinal tree plant in China) is responsible for favoring substrate and biosynthesis of multiple bioactive compounds such as flavonoid glucosides and downstream pigmented compounds such as anthocyanidins [28]. GT1 is also involved in the catalyzation process by glucosylation of flavonols and flavones [28]. Moreover, the Arabidopsis thaliana UGT75C1 and UGT78D2 encode anthocyanin 5-O glucosyltransferase and flavonoid 3-O-glucosyltransferase enzymes respectively that are responsible for biosynthesis of anthocyanidins, pigmented compounds and flavonoids [29]. The overexpression of anthocyanin 3'-O-glucosyltransferase (3'GT) from Gentian (Gentiana triflora) in petunia showed accumulation of blue and purple color anthocyanins in the flower of transgenic petunia (Petunia hybrida) [30]. UGTs genes are directly involved anthocyanin and flavonol glycoside biosynthesis in Arabidopsis thaliana [31].

Based on previous published transcriptomic and gene expression studies on citrus $[2,13,15,32]$ we have selected key genes from the phenylprepanoid pathway; in addition, our gene expression and metabolic data showed that the sweet orange Cs-UGT78D3 gene was differentially expressed (among the selected genes) and correlated with metabolic data (Additional file 1 and Additional file 2). So, we have chosen Cs-UGT78D3 gene encoding UDP-GLUCOSYL TRANSFERASE from sweet orange (Citrus sinensis) to overexpress in Arabidopsis thaliana to evaluate its function. This study will help to understand the metabolic biosynthesis, regulation of genes and possible tolerance role of UDP-GLUCOSYL TRANSFERASE gene towards the stress; in addition, it also facilitates pharmacological industry and assists metabolic engineering to breed a cultivar with increased protective metabolites (phytochemicals) in citrus.

\section{Results}

\section{Selection and overexpression UGTs gene}

In Citrus sinensis, the UGTs genes regulations are positively correlated with flavonoids and anthocyanidins accumulation [33]. Additionally, citrus UGTs genes are involved in metabolism [34] and expressed during growth and development [35]. The citrus UGTs are involved in flavonoids biosynthesis $[35,36]$ and stimulates the anthocyanin biosynthesis in citrus [37]. Based on our (Additional file 2) and published transcriptome data [38], we have selected UGTs genes and confirmed that the UGT78D3 gene was differentially expressed in citrus specie (Citrus sinensis) by quantitative real time PCR (qRT-PCR) (Additional file 1). Thus, one UGTs gene was selected to overexpress in Arabidopsis thaliana to evaluate its function.

Transgenic Arabidopsis plants were selected at $T_{1}$ generation, on MS + kanamycin medium for positive transgenic plant screening, and for further confirmation of transformed plants we did PCR by CaMV35S forward and reverse Cs5g24820 gene-specific primer. At $\mathrm{T}_{2}$ generation, three independent transgenic lines (OX-1, OX-5 and OX-7) were selected based on gene expression and PCR results. Furthermore, $\mathrm{T}_{4}$ generation was produced for light stress experiment. According to qRT-PCR results, the Cs-UGT78D3 gene was more than 25 folds up-regulated in all transgenic lines as compared to wild type (Fig. 1a). 


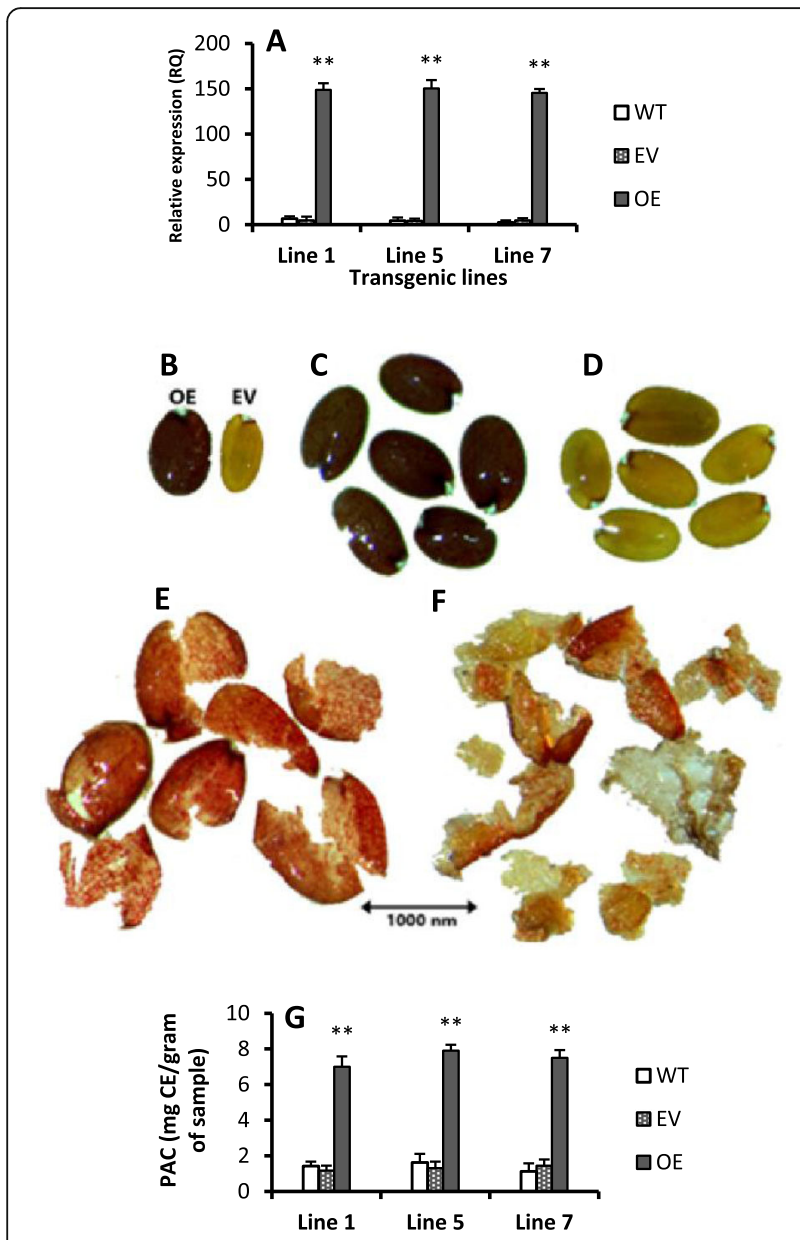

Figure 1 Overexpression of Cs-UGT78D3 gene promotes proanthocyanidins accumulation in Arabidopsis. a Three individual lines showing the overexpression (OE) of Cs-UGT78D3 gene (b) The OE and EV (empty vector) seed showed distinct color (c) OE seeds showing dark brown color (d) Wild type seeds showing pale yellow color (e) Vanillin assay of OE seed coats showing red color on each segment of seed coat (f) In wild type seed, only seed coats margins showing red color while the rest of seed coat color remained pale yellow (g) Proanthocyanidins were significantly increased in the seed coats. Values are mean of three replicates \pm SE and Student's t-test was used to compare 78D3-OE and WT, $p<0.01$. $\left(^{* *}\right)$ Highly significant. WT: Wild type, EV: Empty vector, OE: Overexpression

\section{Overexpression of UDP-GLUCOSYL TRANSFERASE gene} promotes proanthocyanidins accumulation in seed coats

The seed coats color of transgenic Arabidopsis $\mathrm{T}_{2}$ lines becomes brownish as compared with empty vector seeds (Fig. 1b) and was also significantly differentiated from the wild type seed color which was pale yellow (Fig. 1d). At $T_{3}$ and $T_{4}$ generation, the seed coat color was stabilized i.e. dark brown (Fig. 1c). Generally, high accumulation of PAs in the Arabidopsis seed testa gives dark brown color to seed coats [39].

Vanillin reacts with leucoanthocyanidins monomers, terminal subunits of PAs, catechins and gives red color [40, 41].
Vanillin assay was conducted on $\mathrm{T}_{3}$ transgenic seeds. Interestingly, after vanillin treatment, the dark brown color of transgenic seed testa, showed distinct red color (Fig. 1e) as compared with wild type seeds (where only seed coat margins showed red color) (Fig. 1f). So, it is confirmed that the brown color of transgenic seed coats is due to PAs accumulation in seed testa (Fig. 1g) than wild type.

High concentration of proanthocyanidins contents (PAC) were observed in seeds of all transgenic lines than wild type (Fig. 1g). Additionally, gene related to proanthocyanidins biosynthesis pathway such as AT5G42800 (TT3), AT2G37260 (TTG2), AT4G09820 (TT8) and AT1G61720 (BAN) were significantly up-regulated (more than 4 folds) in transgenic seeds than wild type seeds (Fig. 2). Up-regulation of TTG2,

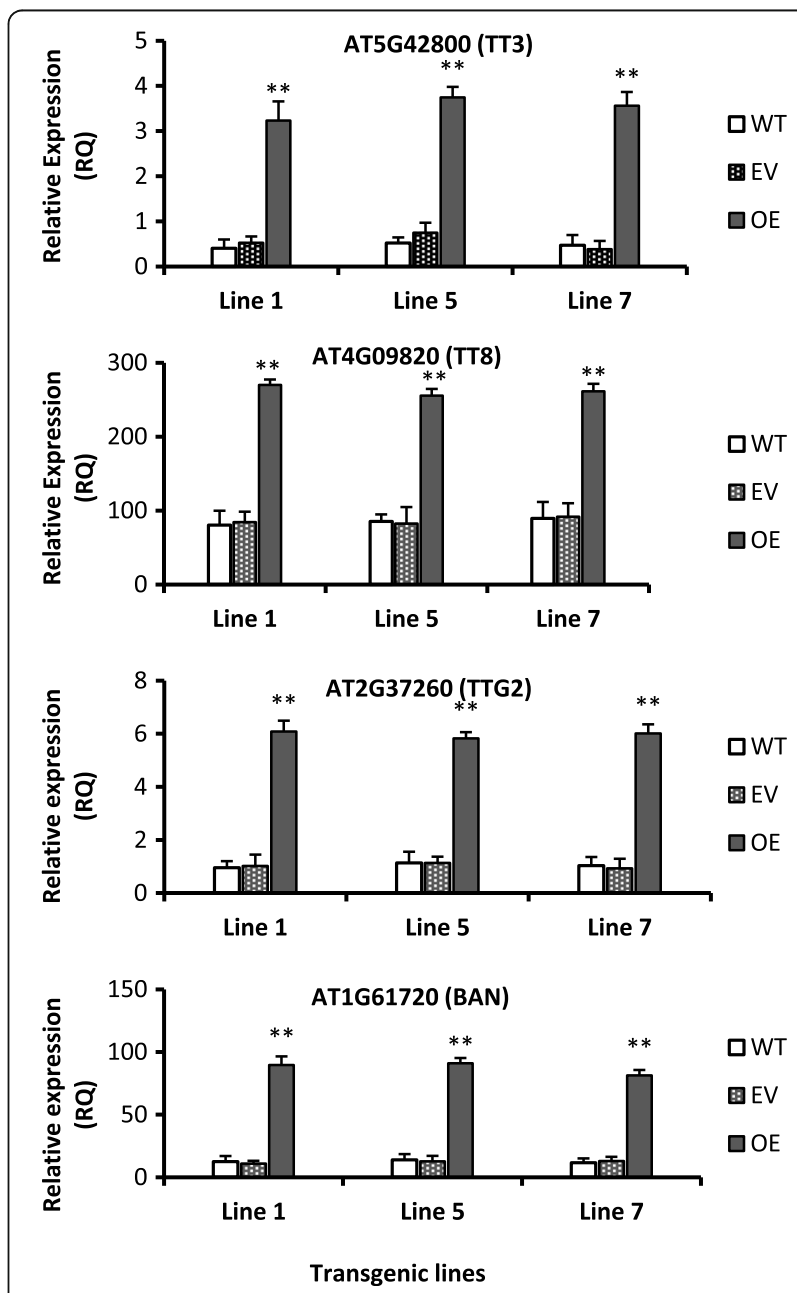

Figure 2 Genes involved in the regulation of anthocyanins and proanthocyanidins biosynthesis upregulated in the transgenic Arabidopsis without light stress. Values are mean of three replicates \pm SE and Student's t-test was used to compare 78D3-OE and WT, $p$ $<0.01$, (**) Highly significant. Gene IDs were taken from Arabidopsis genome website TAIR (https://www.arabidopsis.org/). TT3 or DFR: Dihydroflavonol 4-reductase; TT8: Transparent testa 8; TTG2: Transparent testa glabra 2; BAN: BANYULS. WT: Wild type, EV: Empty vector, OE: Overexpression 
TT8 and BAN during seeds formation will facilitates high accumulation of proanthocyanidins in the seeds coats of Arabidopsis thaliana [42, 43].

\section{High level of phenolic, flavonoid and anthocyanins in transgenic plants}

Higher concentration of total flavonoid (Fig. 3b) and total phenolic contents (Fig. 3c) were observed in transgenic lines as compared to wild type. According to qRT-PCR expression data, the Cs-UGT78D3 gene was more than 25 folds (Fig. 1a) and some genes related to flavonols biosynthesis pathway such as AT3G55120 (TT5), AT3G51240 (TT6) and AT5G07990 (TT7) were induced 2-5 folds in all transgenic lines as compared with wild type (Additional file 3). TT5 is involved in the flavonoid and anthocyanin biosynthesis pathway [44]. The high concentration of total anthocyanin contents (TAC) (Fig. 3a) and total flavonoid contents (TFC) (Fig. 3b) in the leaves with significantly up-regulation of genes related to flavonoids pathways (Fig. 2) in all transgenic lines indicates that this gene is involved in increasing the total anthocyanin and flavonoid contents. Many plant phenolic and flavonoid compounds

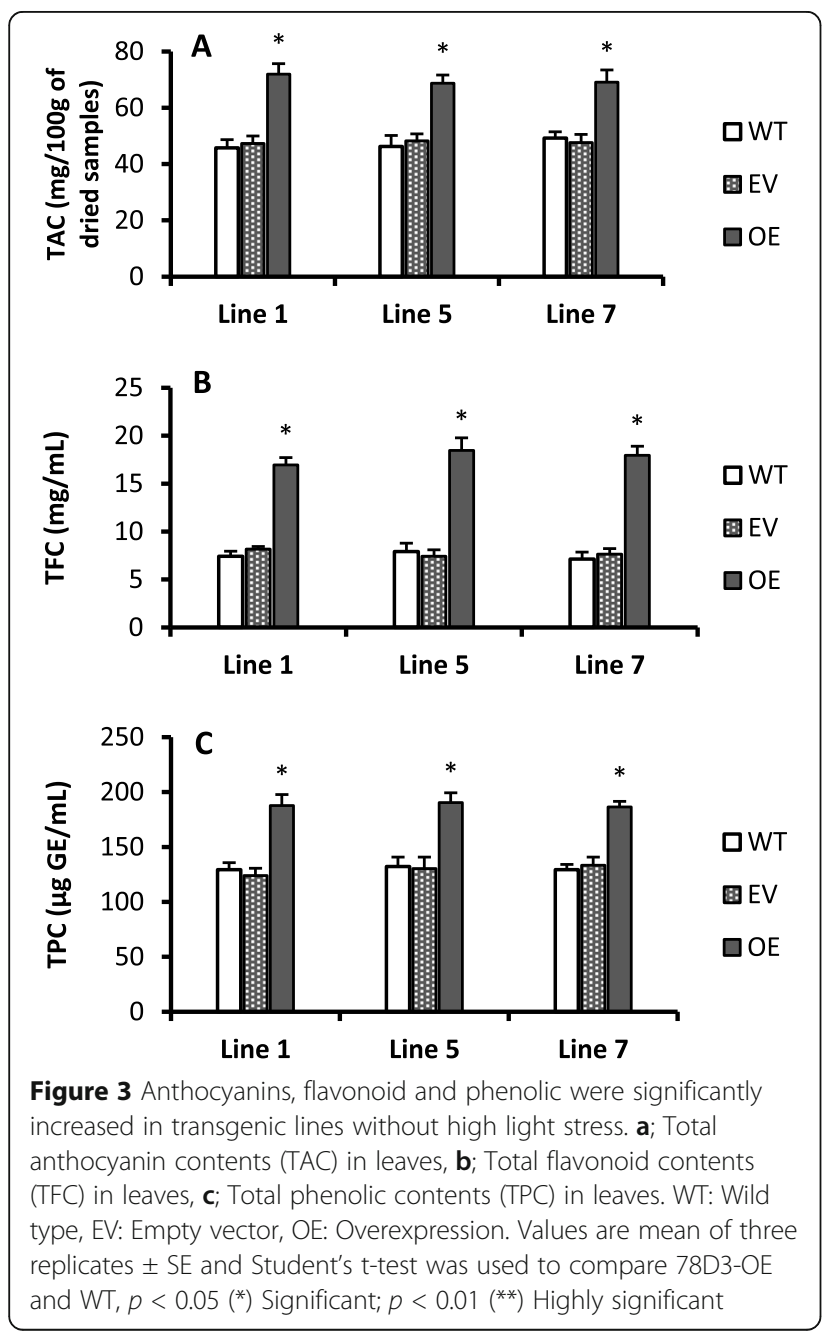

possess significant antioxidant properties that help plants to alleviate the free radical damage produced during light stress [17].

Total anthocyanin contents (TAC) was significantly increased in all transgenic lines as compared with wild type (Fig. 3a). The TT3, TT8, AT3G28430 (TT9) and BAN were significantly induced (more than 4 folds) in the seeds and leaves of all transgenic lines as compared to wild type (Figs. 2 and 4). Moreover, AT5G41315 (GL3) and TTG2 were also significantly induced more than 4 folds in all transgenic lines than wild type. However, 2 fold or less than 2 fold increments has been observed in AT4G22880 (ANS), AT1G17260 (AHA) and AT5G05600 genes expression in transgenic lines than wild type (Additional file 3). The ANS, AHA and AT5G05600 genes are directly or indirectly involved in the anthocyanin biosynthesis (https:// www.arabidopsis.org/). The TT3 and TT5 genes are involved in anthocyanin biosynthesis [44]. The metabolic and gene expression results revealed that Cs-UGT78D3 gene is involved in inducing the flavonoid and anthocyanins biosynthesis pathway to accumulate more metabolites in transgenic Arabidopsis.

\section{Metabolic response of transgenic Arabidopsis against light stress}

TPC, TFC, TAC were increased significantly under 14 days high light stress (HLS) in all transgenic lines than wild type (Fig. $5 \mathrm{c}$-e). In addition, all transgenic lines accumulated significantly high concentration of TAC than wild type after HLS (Fig. 5e). Moreover, all the transgenic lines showed dark purple color phenotype after HLS (Fig. 6b) whereas the wild type and empty vector leaves showed chlorosis and shrink phenotype (Fig. 6b, c). Additionally, after 14 days of light stress, all transgenic lines showed high expression of many genes related to anthocyanin biosynthesis pathway such as TT8, TT9, BAN (Fig. 4). Moreover, the TT3, TT8, TT9, BAN, TTG2 and GL3 genes (Fig. 4) were highly induced (2-15 folds) after high light stress in all transgenic lines and these genes are involved in proanthocyanidins and anthocyanins biosynthesis pathway (Fig. 6d). Anthocyanins are water soluble color pigment which has strong photoprotective properties and probably that is the phenomena behind the HLS tolerance of transgenic lines. Moreover, it was also previously reported that the anthocyanin compounds processes strong antioxidant properties and scavenging the free radicals produced during HLS [45]. So, our phenotypic, metabolic and gene expression data supports that flavonoids and anthocyanin were significantly accumulated in all transgenic lines after HLS.

Chlorophyll degradation was slower and antioxidant activity was higher in transgenic Arabidopsis in response to high light stress. Chlorophyll a and b were decreased dramatically in wild type and empty vector lines after 14 days of HLS; but all the transgenic lines maintained high 


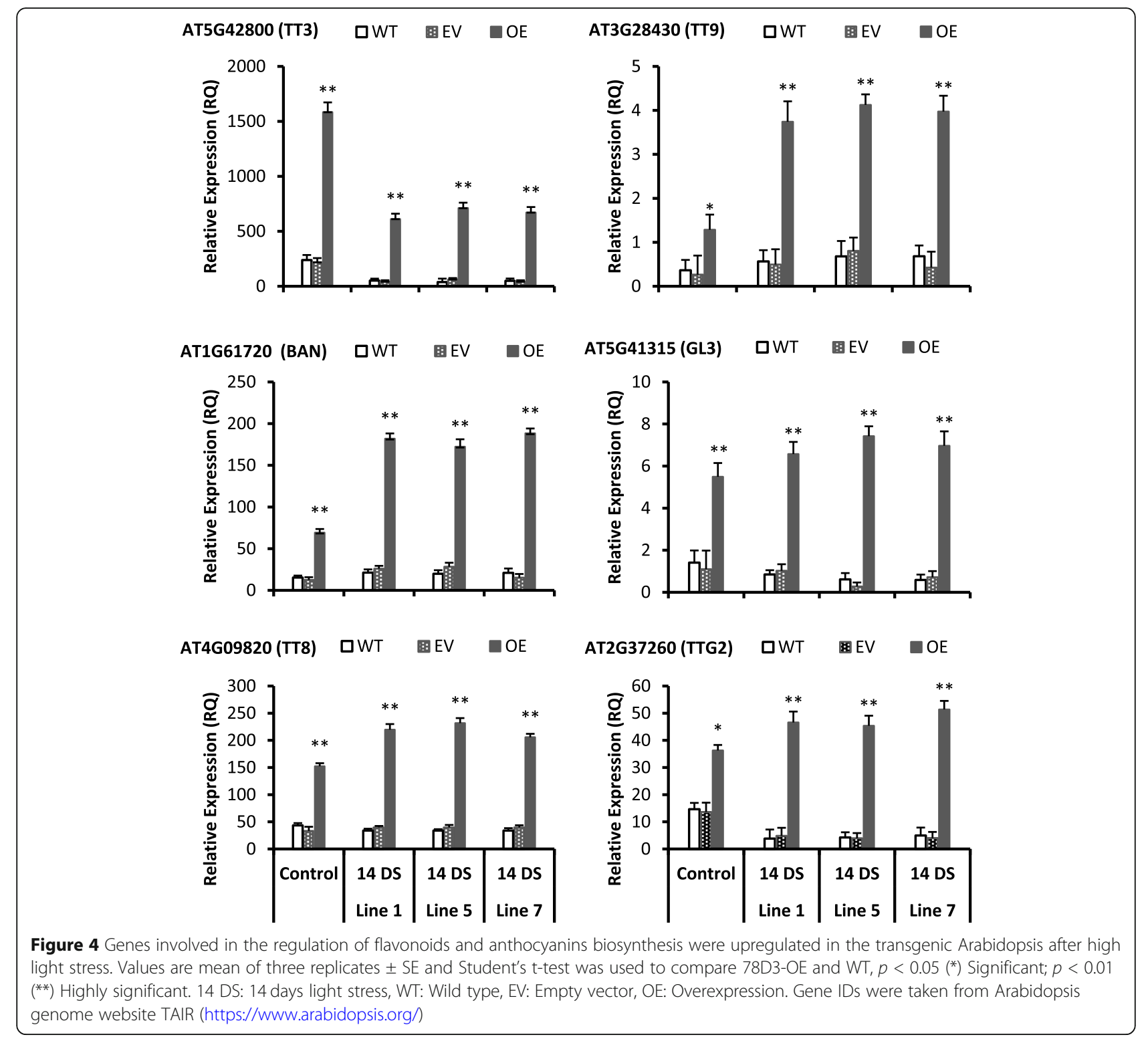

level of chlorophyll a and b than wild type (Fig. 5a, b). Rapid degradation of chlorophyll, due to environmental stresses shows that the plants are more prone to oxidative stress with lower light harvesting capability $[45,46]$. Our results showed rapid degradation of chlorophyll a and b with high level of superoxide radicals (Fig. 5i) in wild type plants while all transgenic lines possess high level of chlorophyll $\mathrm{a}$ and $\mathrm{b}$ with lower level of superoxide radicals (Fig. 5i) after 14 days of HLS; which clearly showed that wild type plants were under high stress and more prone to free radical damage than transgenic Arabidopsis lines (Fig. 5a).

The free radical scavenging potential during HLS has been examined in wild type and transgenic Arabidopsis lines. The antioxidant activity and capacity were extraordinarily higher in all transgenic lines after 14 days of
HLS than wild type (Fig. 5f, g). In addition, the antioxidant activity and capacity were non-significantly reduced after 14 days of high light stress in wild type and empty vector lines than control (without stress) wild type and empty vector lines respectively (Fig. 5f, g). These results showed that the HLS transgenic Arabidopsis lines have high free radicals scavenging potential, as compared with wild type. Moreover, superoxide radicals were significantly lower in all transgenic lines after HLS than wild type (Fig. 5i). Abiotic stress tolerance is associated with high antioxidant activity and capacity [46]. Therefore, our results indicated that the wild type plants were underwent damage under high light stress due to high free radicals (Fig. 5i) whereas the transgenic lines show high antioxidant potential and are more tolerant to the stress. 


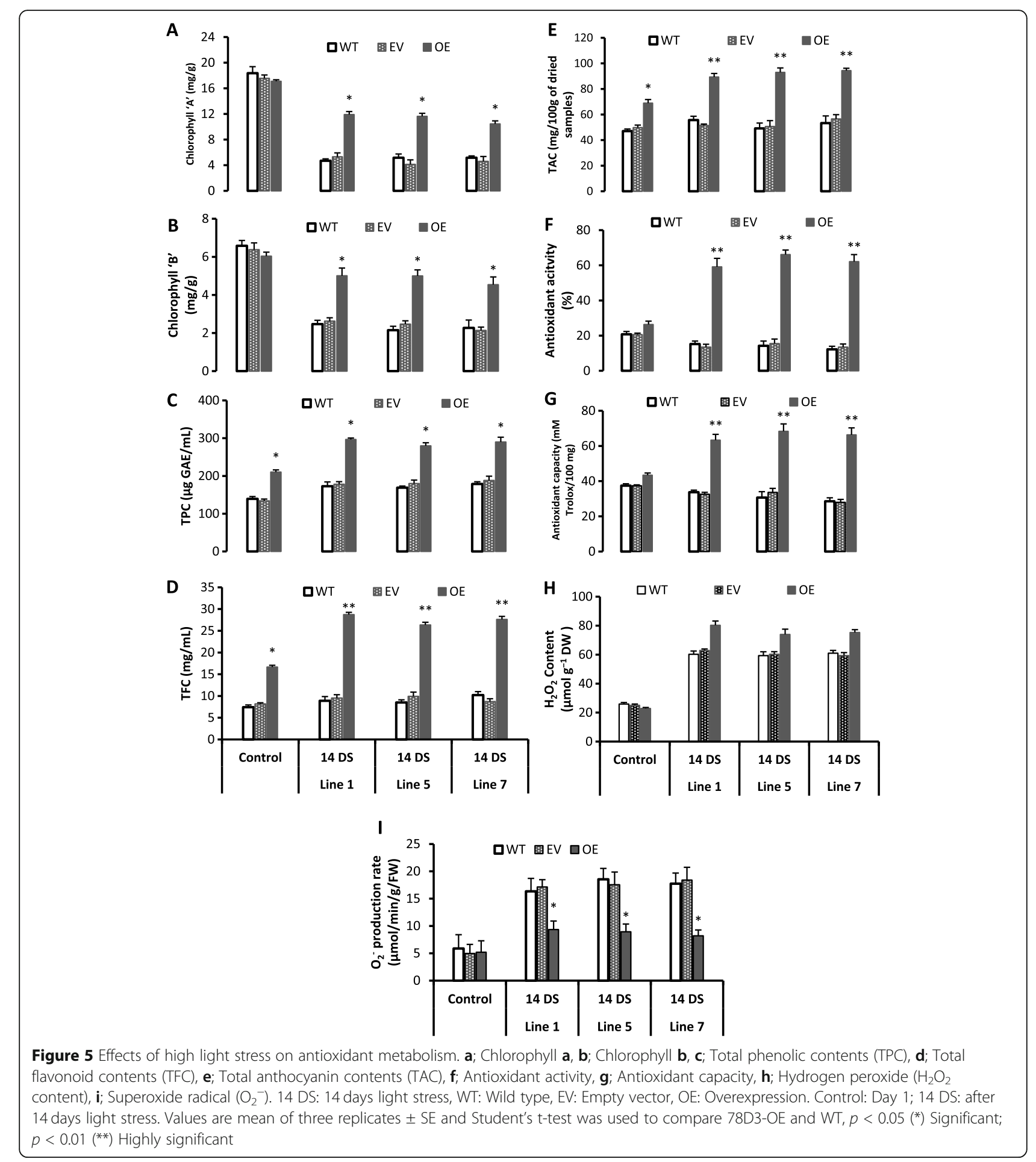

The Hydrogen peroxide contents were increased in HLS transgenic lines than control transgenic lines and similar trend was observed in wild type plants (Fig. $5 \mathrm{~h}$ ). $\mathrm{H}_{2} \mathrm{O}_{2}$ is vital metabolite in plants that is involved in governing various defense responses against abnormal conditions such as cell signaling and sensing functions [47]. Recent researches have reported that $\mathrm{H}_{2} \mathrm{O}_{2}$ has been supposed to be involved in protecting plants during abiotic stresses by triggering the signal transduction pathways that facilities crops plant to acclimation in stressed environment $[47,48]$.

\section{Discussion}

In Arabidopsis thaliana, UGTs gene expression are positively correlated with anthocyanin biosynthesis and flavonol 

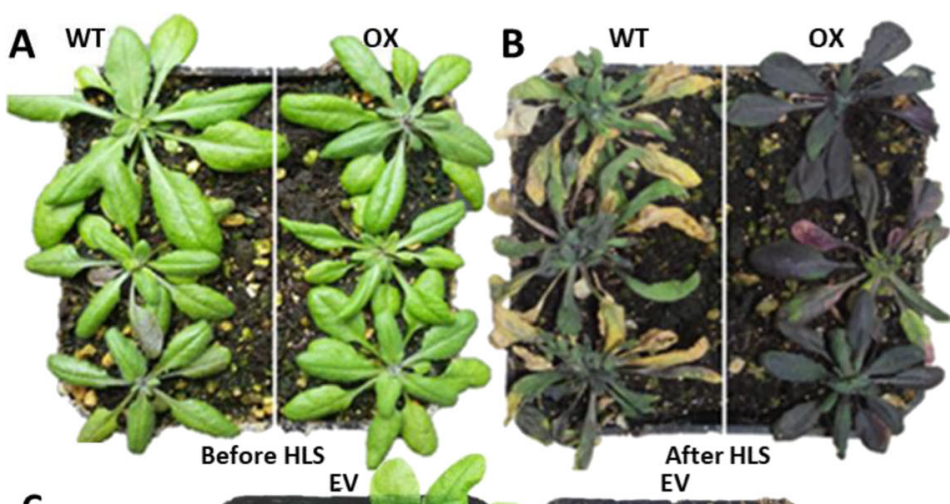

C
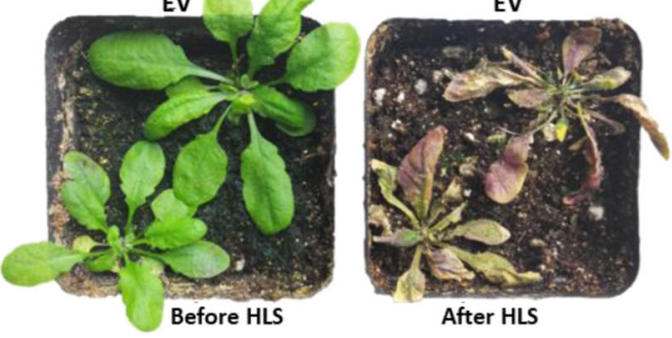

D

Dihydrokaempferol

Anthocyanins pathway genes
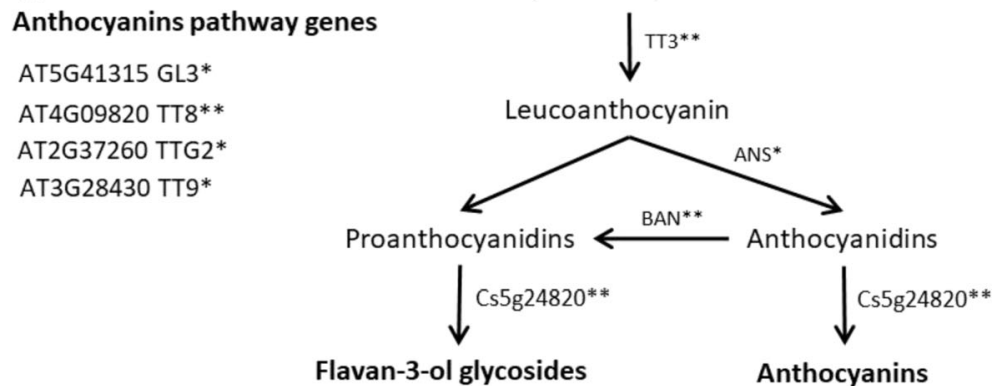

Figure 6 Phenotype of Arabidopsis plants after high light stress and the potential function step of citrus Cs-UGT78D3 in anthocyanins biosynthesis pathway (a) 25 days old wild type (WT) and overexpressed (OX) Arabidopsis plants (b) After 14 days of high light stress WT and OX plants (c) HLS effects on empty vector (EV) lines (d) Assumed functional step of citrus UDP-GLUCOSYL TRANSFERASE gene (CS5g24820) (Metabolic pathway has been made from KEGG www.genome.jp/kegg/pathway; TAIR https://www.arabidopsis.org/and [19]). Student's t-test was used to

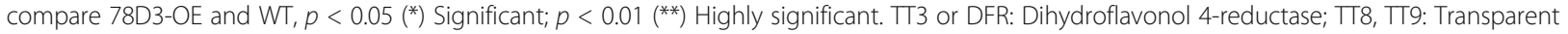
Testa 8, 9; ANS: anthocyanidin synthase; BAN: Banyuls; TT9 and TTG2: triggers the accumulation of brown colored proanthocyanidins; GL3: TT8 and GL3 are basic helix-loop-helix (bHLHs) transcription factors that influence anthocyanin accumulation

glycoside accumulation [31]. The overexpression of glycosyl-transferase gene in Citrus sinensis revealed high accumulation of flavonoid glucosides and anthocyanidins biosynthesis [33]. Moreover, the UDP glucosyltransferase gene from Citrus unshiu (Marc.) is involved in metabolism and converts the limonoid aglycones into glucosides [34]. Delay expression of UGTs gene will delay the bitterness in citrus fruits [49]. The glucosyltransferase genes were significantly expressed during different growth and developmental stages of Citrus paradisi (cv. Duncan) and positively correlated with flavonoids biosynthesis [35]. The UGT708G1 from kumquat (Fortunella crassifolia) and UGT708G2 from satsuma mandarin (Citrus unshiu) are involved in flavonoids accumulation [36] and regulates the anthocyanin pigments biosynthesis [37] and in citrus UGTs genes respond to different environmental conditions [50, 51]. To the author's knowledge, this study provided an evidence of UGT78D3s' function in both anthocyanins and proanthocyanidins.

Accumulation of proanthocyanidins is governed by TT2, TT8, and TTG2 genes, and some downstream PAs biosynthetic genes and these genes are also involved in the flavonoid biosynthetic pathway [42]. Moreover, transcription factor such as TT8 regulates the UGTs genes to accumulate the proanthocyanidins and anthocyanins in Arabidopsis [42]. Generally, PAs were accumulated in the inner layer of seed testa and gives dark brown color to Arabidopsis seeds [42]. The terminal subunits of PAs react with vanillin and produces red color [40, 41]. PAs are colorless flavonoid polymers and PAs oxidation gives brown color to mature seeds [39]. In addition, PAs protect seeds from unfavorable environmental condition and enhance seed longevity [43]. The transgenic seeds showed dark 
brown color phenotype whereas wild type and empty vector seeds displayed pale yellow color (Fig. 1b-d). Moreover, vanillin assay showed accumulation of PAs in all transgenic seed coats (Fig. 1e). In addition, the proanthocyanidins contents were also high in seeds of all transgenic lines (Fig. 1g).

Our results showed that the TT8 and TTG2 both genes were up regulated in the transgenic lines as compared with wild type (Fig. 2). TT8 is a regulation factor which is involved in regulating the biosynthesis of flavonoids, proanthocyanidins and anthocyanins [42]. The brown color of Arabidopsis seeds are mainly due to PAs and their biosynthesis is governed by TT8 and TTG2 genes and these factors are involved in regulating the various biosynthetic gene of PAs pathway [42]. In addition, TT8 also regulates the JAZ (Jasmonate ZIMdomain) proteins to triggers the anthocyanin production. The TTG2 and TT8 expression are essential for BAN correct expression to accumulate PAs in seeds [42].

The Poinsettia (Euphorbia pulcherrima) leaves accumulates high level of water soluble anthocyanin pigments and withstand under high light stress, signifying the photodefensive role of anthocyanin compounds [45]. Our results also showed high accumulation of anthocyanin content (Fig. 3a and 5e) and showed dark purple color in leaves of all transgenic lines (Fig. 6b) after HLS than wild type and empty vector (Fig. 6c); which demonstrate that overexpression of Cs-UGT78D3 gene is involved in anthocyanin accumulation and protects plants from HLS damage. In addition, the real time PCR also showed many folds increment of TT8, TT9, BAN genes in all transgenic lines (Figs. 4 and 6d) and these genes are involved in the biosynthesis of anthocyanins.

The high light stress led to rapid degradation of chlorophyll $\mathrm{a}$ and $\mathrm{b}$ contents in the leaves of soybean (Glycine $\max$ ) plants with decreased efficiency of photosynthetic apparatus [52]. In a recent study, similar results have been observed in Poinsettia (Euphorbia pulcherrima) plants when they were exposed to high light stress [45]. The plants who possess high chlorophyll contents and maintained high level of antioxidant activity and capacity can tolerate prolong abiotic stresses [53]. Our results also showed that high light stressed transgenic lines possesses significantly higher level of antioxidant activity (Fig. 5f, g), chlorophyll a and b contents (Fig. 5a, b) with lower superoxide radicals (Fig. 5i) than HLS wild type plants. Abiotic stress decreases the antioxidant potential, chlorophyll contents and also lowers the high harvesting ability of plants which ultimately triggers the production reactive oxygen species (ROS) and cause serve damage to cells (due to free radicals) [53].

Excessive light stress accumulates large amount of phenolic and flavonoid compounds such as flavonols in leaves, which has significant antioxidant capability to scavenging the ROS generated during abiotic $[18,23]$ and biotic stress [19]. Flavonols behaves as photo-protectants and possesses strong antioxidant activity that's helps to counters the ROS species to fight against the oxidative stress caused by excessive light stress [17]. Additionally, the Poinsettia accumulates anthocyanins in leaves after HLS, that indicates strong photoprotective role of anthocyanins [45]. Flavonoids and anthocyanin holds resilient antioxidant properties and contributes to photoprotection [54]. Our metabolic results showed high level of anthocyanin and flavonoid contents in all transgenic lines compared to wild type (Fig. 3a, b). These outcomes showed that the overexpression of citrus CsUGT78D3 gene is strongly linked with the flavonoids and anthocyanin biosynthesis; moreover, the gene expression data showed high expression of some genes involved in flavonol and anthocyanin biosynthesis (Fig. 4), that also supports the metabolic results (Fig. 3a, b, c). The transgenic plants become acclimatized to stress situation by triggering the flavonoids and anthocyanin biosynthesis and makes transgenic lines more tolerant against the HLS.

Recent researches have reported some positive and key roles of $\mathrm{H}_{2} \mathrm{O}_{2}$, by stimulating the complex signaling transduction pathways leading to systemic acquired resistance and stress acclimation under abiotic and biotic stresses [47, 48]. Moreover increment in $\mathrm{H}_{2} \mathrm{O}_{2}$ level will also induce some defense related genes [48]. Our results have showed high $\mathrm{H}_{2} \mathrm{O}_{2}$ contents in high light stress transgenic lines as compared with wild type (Fig. 5h). In addition, all transgenic lines showed high antioxidant activity and capacity (Fig. 5f, g), after HLS. This shows that transgenic lines possess better and strong free radical scavenging properties than wild type. This clearly demonstrates that under high light stress the transgenic lines showed less oxidative stress with better free radical scavenging capability than wild type Arabidopsis plants. Therefore, biochemical, metabolic, phenotypic and gene expression data supports that all transgenic lines were tolerant to high light stress; due to high level of anthocyanin and flavonoids with better antioxidant potential than wild type.

\section{Conclusion}

Overexpression of Cs-UGT78D3 showed dark brown color in seeds of all transgenic Arabidopsis lines due to proanthocyanidins accumulation. Moreover, all transgenic lines showed significantly high level of total anthocyanin and total flavonoid contents in leaves. After 14 days of high light stress, the transgenic Arabidopsis lines showed significant anthocyanins accumulation and maintained high antioxidant activity and capacity as compared with wild type. The gene expression data also supported the up-regulation of many flavonoids (flavonol) and anthocyanin biosynthesis genes in transgenic Arabidopsis lines than wild type. We demonstrate that overexpression of Cs-UGT78D3 gene accumulates proanthocyanidins in 
transgenic seed coats and confers high light stress tolerance by accumulating total anthocyanin and flavonoid contents with improved antioxidant potential than wild type. This study also provided an ideal candidate gene for future metabolic engineering to breed a cultivar with increased protective metabolites (phytochemicals).

\section{Methods}

\section{Plant materials and growth conditions}

In this study, wild type Arabidopsis thaliana ecotype Columbia-0 (Col-0) (Arabidopsis seeds purchased online www.arashare.cn) was used to overexpress the Citrus sinensis UDP-GLUCOSYL TRANSFERASE (Cs5g24820) gene (citrus seeds were taken from citrus genomic lab in Huazhong Agricultural University). The wild type (WT) Arabidopsis seeds were sterilized with $70 \%(\mathrm{v} / \mathrm{v})$ ethanol for $10 \mathrm{~min}$ followed by ethanol $100 \%$ (v) for $8 \mathrm{~min}$, and then the seed were washed 4 times with double deionized water. Then the seeds were pour out on the Murashige and Skoog (MS) medium petri dishes plate containing $4.43 \mathrm{~g}$ MS (dried basal medium with vitamins supplement phyto-technology laboratories); $25 \mathrm{~g}$ sucrose; $10 \mathrm{~g}$ agar for 1 liter $1 \%(\mathrm{w} / \mathrm{v})$ and petri plates were left in the growth chamber having $20-22^{\circ} \mathrm{C}$ and then after 10 days the plants were transferred into the small pots (soil). Then the plants were grown in growth chamber for 3 weeks having an irradiance of $120 \mu \mathrm{mol}$ quanta $\mathrm{m}^{-2}$ per sec, with $70 \%$ relative humidity and temperature about $22 \pm 3{ }^{\circ} \mathrm{C}$, under $16 / 8 \mathrm{~h}$ light and dark period.

\section{Vector construction and agrobacterium transformation}

The T-DNA Gateway technology (Invitrogen) pK7WG2D vector, was constructed (to overexpress the flavonol transferase gene of Citrus in Arabidopsis), which contains green fluorescent protein (GFP) and also confers kanamycin resistance (that helps for plant visual or manual selection) due to neomycin phosphotransferase II (nptII) gene [55]. By using cDNA, coding region of Cs-UGT78D3 was amplified by means of PCR using gene specific primers, then the plasmid was extracted and first cloned into pDONR221 and then intervened by L. $\mathrm{R}$ clonase enzymatic reactions (invitrogen) (as prescribed by manufactures instructions) and cloned into binary Gateway Vector pK7WG2D. After that the pK7WG2D was transferred into GV3101 (Agrobacterium strain) and then transformed into the Arabidopsis, by dipping the wild type Arabidopsis flowers in Agrobacterium solution via floral dip method [56].

\section{Transgenic lines and light stress conditions}

The transgenic Arabidopsis lines were developed via Agrobacterium-mediated transformation. The wild type (WT), transgenic Arabidopsis line 35S:PK7WG2D (empty vector), and three independent overexpressed 35S: PK7WG2D-UGT78D3 lines (OX-1, OX-5, OX-7) have been prepared by cross checking and selfing to get $\mathrm{T}_{4}$ stage transgenic plants for 14 days of light stress experiment. In each stage, the Arabidopsis seeds were first sown on MS medium having Kanamycin $(50 \mathrm{mg} / \mathrm{L})$ to get positive plants and later it was confirmed by qRT-PCR expression analysis. So, for light stress experiment, the 25 days old wild type, empty vector and transgenic plants were used and subjected to high light stress for 14 days in a growth camber with following conditions (Fig. 6a, c); 50, 000 Lux light stress having $16 \mathrm{~h}$ light and $8 \mathrm{~h}$ dark, with $70 \%$ relative humidity and temperature about $24 \pm 2{ }^{\circ} \mathrm{C}$. On day 1 and after 14 days of HLS, the leaves samples were collected and immediately frozen by means of liquid nitrogen and preserved at $-80^{\circ} \mathrm{C}$ for biochemical, metabolic and gene expression analysis.

\section{DNA extraction and PCR analysis}

DNA was extracted by $2 \%$ CTAB method $[57,58]$. Fifty to one hundred milligram $(\mathrm{mg})$ fresh Arabidopsis leaves were crushed into fine powder and followed by addition of $700 \mu \mathrm{l}$ of DNA buffer than $90 \mathrm{~min}$ incubation at $65^{\circ} \mathrm{C}$. After that $800 \mu \mathrm{l}$ of chloroform-isoamyl alcohol (24:1) was added and then after $10 \mathrm{~min}$ of gentle inversions, centrifuged at $10,000 \mathrm{rpm}$ for $10 \mathrm{~min}$ and DNA pellet was taken [58]. PCR was performed by using PCRMaster mix (dream tag green-Thermo Scientific) according to manufactures instructions.

\section{RNA extraction and quantitative real time PCR analysis}

Fresh leaves were immediately frozen into liquid nitrogen after harvesting and then used for RNA extraction by using TRIzol RNA (extraction kit) reagent (Takara). RNA was extracted as described by manufacture's instruction on TRIzol kit. After total RNA extraction, the complementary DNA (cDNA) was synthesized by using $1 \mu \mathrm{g}$ of total RNA by means of (Vazyme, R223-01) HiScript II QRT (reverse transcriptase) SuperMix for qPCR (+gDNA wiper) methodology. After cDNA synthesis all the cDNA samples were stored at $-80^{\circ} \mathrm{C}$ for further expression analysis (qPCR). For qRT-PCR was conducted by using SYBR Green (YEASEN Biotec. Co.Ltd.) PCR Master mix and all standard procedure were adopted as described by producer's instructions. The qRT-PCR was done with three technical replicates (light cycler 480 multi-well plate 384white) and performed by means of light cycler $480 \mathrm{II}$ instrument (Roche). Relative expressions of pathway genes were calculated by means of $2-\Delta \Delta C t$ methodology [59]. Arabidopsis $\beta$-actin gene was used as an internal reference gene. The qRT-PCR primers details are documented in Additional file 4.

\section{Vanillin assay for proanthocyanidins determination}

For vanillin assay, wild type and over-expressed seeds were taken in $1.5 \mathrm{ml}$ of centrifuge tube followed by addition of I 
milliliter dye solution $1 \%$ vanillin (w/v) in $6 \mathrm{M}$ of hydrochloric acid ( $\mathrm{HCl})$ [39]. About one layer of seeds has been taken to cover the bottom of $1.5 \mathrm{ml}$ tube. Incubate the mature seeds for 1 hour at room temperature. After incubation, the seeds coats were gently separated with dissecting needle and tweezers on glass-slide by using stereomicroscope (OLYMPUS, SZ61 model). Then the light microscope (OLYMPUS, BX61 model) was used to photograph the stained seeds coats [60].

\section{Determination of proanthocyanidins contents (PAC)}

Proanthocyanidins concentration was estimated by grinding $20 \mathrm{mg}$ of Arabidopsis seeds with liquid nitrogen followed by adding $1 \mathrm{ml}$ of extraction buffer (acetone 70\%: water 29.5\%: acetic acid 0.5\%) with slightly modifications [61]. Then the samples were centrifuges at $4000 \mathrm{rpm}$ and supernatant was taken for proanthocyanidins quantification. The reaction mixture contained $200 \mu \mathrm{l}$ of above prepared solution followed by addition of $3 \mathrm{ml}$ of $0.5 \%(\mathrm{w} / \mathrm{v})$ vanillin dissolved in methanol and $1.5 \mathrm{ml}$ of $4 \%(\mathrm{v} / \mathrm{v}) \mathrm{HCl}$. Then after $15 \mathrm{~min}$ the absorbance was taken at 550 $\mathrm{nm}$ on spectrophotometer (model UV-1800, Shimadzu corporation, Japan) whereas pure methanol was used as blank. The standard curve was generated by using catechin and the PAC value was expressed in milligrams of catechin equivalents (mg CE/gram of sample).

\section{Determination of chlorophyll content}

For chlorophyll 'a' and 'b' estimation, the Arabidopsis leaves tissues $(500 \mathrm{mg})$ were grounded into fine powder by using $10 \mathrm{ml}(\mathrm{mL})$ of $80 \%(\mathrm{v} / \mathrm{v})$ acetone [62], followed by $4 \mathrm{~h}$ of incubation at room temperature (RT) in dark. After that the sample tubes were centrifuged for $5 \mathrm{~min}$ at $12,000 \mathrm{rpm}$, and the supernatant was collected into a new tube then its absorbance was measured at $645 \mathrm{~nm}$ and $663 \mathrm{~nm}$ on spectrophotometer $(80 \%(\mathrm{v} / \mathrm{v})$ acetone was used as blank). Chlorophyll content was expressed in milligram per liter and calculated by using following formula:

Chlorophyll a $=$ OD663 $\times 12.7-O D 645 \times 2.69(\mathrm{mg} / \mathrm{L})$, Chlorophyll b $=$ OD645 $\times 22.9-$ OD663 $\times 4.68(\mathrm{mg} / \mathrm{L})$.

\section{Determination of total contents of phenolics and flavonoids \\ Extraction}

$100 \mathrm{mg}$ of leaves tissues were crushed into powdered by using pestle and mortar followed by addition of 5 $\mathrm{mL}$ of $80 \%$ methanol and samples were left for $2 \mathrm{~h}$ at RT on an orbital shaker at $200 \mathrm{rpm}$ followed by centrifugation [63]. The supernatant mixture was collected into a new tube while the remaining pellet was again extracted with the same procedure (with similar conditions) as described earlier and both supernatants were combined in $15 \mathrm{~mL}$ tube, and then used for estimation of total phenolics and total flavonoid contents.

\section{Total phenolics contents (TPC)}

Folin-Ciocalteu reagent (FCR) based methodology was used for determination of total phenolics content [63]. Three hundred microliter of above prepared extract was taken in a fresh $10 \mathrm{~mL}$ tube and mixed with (10-fold diluted FCR with distilled water) $2.25 \mathrm{~mL}$ of FCR followed by $5-10$ gentle inversions and $5 \mathrm{~min}$ incubation at RT. Then I added $2.25 \mathrm{~mL}$ of sodium carbonate $\left(\mathrm{Na}_{2} \mathrm{CO}_{3}\right)(60 \mathrm{~g} / \mathrm{L})$ solution into the reaction mixture. Then after $2 \mathrm{~h}$ of incubation at RT the absorbance was taken at $725 \mathrm{~nm}$ by means of spectrophotometer (model UV-1800, Shimadzu corporation, Japan). Standard curve was generated by using gallic acid (GA) and results were defined as milligram of GA-equivalents (GAE) per 1 gram of dried weight of plant leaves (mg GAE/g).

\section{Determination of total flavonoid content (TFC)}

Total flavonoid content was measured by means of colorimetric method with minor modification [64]. About $500 \mu \mathrm{l}$ of the prepared methanolic extract was taken into $10 \mathrm{~mL}$ new tube followed by addition of $2.25 \mathrm{~mL}$ of distilled water and mix well then added $150 \mu \mathrm{l}$ of $5 \%$ sodium nitrite $\left(\mathrm{NaNO}_{2}\right)$ solution followed by $6 \mathrm{~min}$ incubation at RT. After that $300 \mu$ l solution of $10 \%$ aluminum chloride hexahydrate $\left(\mathrm{AlCl}_{3} \cdot 6 \mathrm{H}_{2} 0\right)$ was added into the reaction mixture with $5 \mathrm{~min}$ of incubation at $\mathrm{RT}$ and then $1000 \mu \mathrm{l}$ of 1 Molar $(\mathrm{M})$ sodium hydroxide $(\mathrm{NaOH})$ was added followed by vertex for $30 \mathrm{~s}$. The reaction mixture absorbance was taken instantly at $510 \mathrm{~nm}$ by means of spectrophotometer (model UV-1800, Shimadzu corporation, Japan). Standard curve was generated by using rutin compound and results were defined as milligram rutin equivalents (RE) per 1 gram of dried plant leaves sample (mg RE/g).

\section{Total anthocyanin contents (TAC)}

For determination of total anthocyanin content $100 \mathrm{mg}$ of leaves tissues were grounded (using liquid nitrogen) by means of mortar and pestle $[65,66]$. After that the samples were re-suspended in five volumes (based on fresh weight) of extraction solution (having $45 \%$ methanol $(\mathrm{v} / \mathrm{v})$ and $5 \%$ acetic acid $\mathrm{v} / \mathrm{v})$ followed by gentle inversion and then centrifuged at $(10,000 \mathrm{rpm})$ for $10 \mathrm{~min}$ at RT. The supernatant solution was collected into a new tube to check the absorbance at $530 \mathrm{~nm}$ and 657 $\mathrm{nm}$ by anthocyanin measurement and chlorophylls respectively thru spectrophotometer (model UV-1800, Shimadzu corporation, Japan). Then by using the following 
formula the anthocyanin contents were measured by correction in the $530 \mathrm{~nm}$ absorbance by chlorophylls:

$$
\begin{aligned}
\mathrm{TAC}_{(\mathbf{m g} / \mathbf{1 0 0 g} \text { of dried weight })} & =(\text { absorbance at } 530 \mathrm{~nm} \\
& -(0.25 \times \text { absorbance at } 657 \mathrm{~nm}) \\
& \times \text { extraction volume }(\mathrm{mL}) \\
& \times 1 / \text { weight of leave tissue sample }(\mathrm{g}) .
\end{aligned}
$$

"For anthocyanin we used 5 times extraction volume and $0.1 \mathrm{~g}$ leave tissue sample.

\section{Antioxidant capacity and activity (DPPH free radical scavenging assay)}

For antioxidant capacity and activity fresh Arabidopsis leaves were ground $(100 \mathrm{mg})$ and homogenized in $1 \mathrm{~mL}$ of extraction solution (ethanol, water, and acetic acid, 70, 29, and $1 \%$ respectively) and then centrifuged [67] with slight modifications. The supernatant was used to calculate antioxidant capacity by using the $30 \mu \mathrm{l}$ of above prepared solution followed by addition of $2.97 \mathrm{~mL}$ of $0.1-\mathrm{mM} 2,2-$ diphenyl-1-picrylhydrazyl (DPPH) followed by $30 \mathrm{~min}$ incubation in dark (in RT). Then the sample absorbance was taken at $517 \mathrm{~nm}$ by means of spectrophotometer (model UV-1800, Shimadzu corporation, Japan). Thirty microliter of extraction solution (without plant sample) in $2.97 \mathrm{~mL}$ of DPPH is used as control. The antioxidant capacity was calculated by generating standard curve of trolox and samples were expressed in (mM Trolox/ $100 \mathrm{mg}$ ). While the antioxidant (free radical scavenging) activity is described by using the following formula:

Antioxidant activity $(\%)=[1-\{$ sample OD/control OD $\}] \times 100$.

\section{Hydrogen peroxide $\left(\mathrm{H}_{2} \mathrm{O}_{2}\right)$}

Hydrogen peroxide was measured by using trichloro-acetic acid (TCA) method [68]. Ground leaves samples $(0.1 \mathrm{~g})$ were resuspended in $1000 \mu \mathrm{l}$ of TCA $(0.1 \%)$ solution in an ice bath and then centrifuged for $10 \mathrm{~min}$ at $10,000 \mathrm{rpm}$. The $500 \mu \mathrm{l}$ of supernatant was taken into a new tube and added $500 \mu \mathrm{l}$ of $10-\mathrm{mM}$ potassium phosphate buffer followed by addition of $1000 \mu \mathrm{l}$ of $1 \mathrm{M}$ potassium iodide (KI) then mix well and checked the absorbance reading at $390 \mathrm{~nm}$ by means of spectrophotometer (model UV-1800, Shimadzu corporation, Japan). The sample absorbance was calculated by comparing the standard curve absorbance of commercial $\mathrm{H}_{2} \mathrm{O}_{2}$. The $\mathrm{H}_{2} \mathrm{O}_{2}$ contents were expressed in micromoles/g of dried samples.

\section{Superoxide radical's determination}

The superoxide radicals $\left(\mathrm{O}_{2}{ }^{-}\right)$were measured in $0.1 \mathrm{~g}$ of fresh leaves tissues [69]. The one unit of superoxide radical was defined as 0.1 units change in absorbance, per min at the corresponding wavelength values. The standard curve was generated by using nitrite ion $\left(\mathrm{NO}_{2}{ }^{-}\right)$. The absorbance was measured at $530 \mathrm{~nm}$ on spectrophotometer (model UV-1800, Shimadzu corporation, Japan).

\section{Statistical analysis}

The Statistix 8.1 (Tallahassee Florida, USA) statistical package was used to analyze the data. The standard error and graphs were made by using Microsoft Excel 2010 program (Microsoft Corp., Redmond, WA, USA). Differences were considered significant at $p<0.05$ and highly significant at $p<0.01$.

\section{Supplementary information}

Supplementary information accompanies this paper at https://doi.org/10. 1186/s12870-019-2212-1.

Additional file 1: Table S1. Showing $\mathrm{qPCR}$ primer sequence used in this study for gene expression analysis. Figure S1. Showing the gene expression pattern in citrus species at different stages. SWO: Sweet orange; AB: Atalantia buxifolia; CG: Citrus grandis. Figure S2. Representing the gene expression results under drought and High light stress on Citrus sinensis leaves. 14 HLS, 14 days of high light stress; 14DDS: after 14 days of drought stress. Values are mean of three replicates \pm SE and Student's t-test was used to compare control and stressed plants $p<0.05$. (*) Significant: $P<0.01\left(^{* *}\right)$ highly significant. Table S2. Showing the details and mode of metabolites used in this study. Figure S3. Heat map and hierarchical cluster analysis (HCA) using the square of peaks of detected metabolites in different citrus germplasm (AB; Atalantia buxifolia, CG; Citrus grandis, and CS; Citrus sinensis). Column represents varieties and row characterized flavonoids and anthocyanins.

Additional file 2: Raw transcriptomic data of 12 key genes: Representing the gene expression pattern data in three citrus species at different stages of development (in seed, leaf, flower and fruit). SWO: Sweet orange; AB: Atalantia buxifolia; CG: Citrus grandis.

Additional file 3: Figure S1. Showing the expression of different genes used in this study. WT: Wild type, EV: Empty vector, OE: Overexpression. Values are mean of three replicates \pm SE and Student's t-test was used to compare 78D3-OE and WT, $p<0.05\left(^{*}\right)$ Significant; $p<0.01\left(^{* *}\right)$ Highly significant. Gene IDs were taken from Arabidopsis genome website TAIR (https://www.arabidopsis.org/).

Additional file 4: Table S1. Showing the gene ID of transcription factor and enzyme that involved in the flavonoid and anthocyanin pathway and their primers sequence used for qRT-PCR.

\section{Abbreviations}

CE: Catechin equivalents; DPPH: 2,2-diphenyl-1-picrylhydrazyl; FCR: FolinCiocalteu reagent; G: gram; $\mathrm{GA}$ : Gallic acid; $\mathrm{H}_{2} \mathrm{O}_{2}$ : Hydrogen peroxide: HLS: High light stress; M: Molar; Mg: milligram; $\mathrm{mL}$ : Milliliter; $\mathrm{O}_{2}^{-}$: Superoxide radicals; OX: Overexpression; PAC: Proanthocyanidins contents;

PAs: Proanthocyanidins; qRT-PCR: Quantitative real time PCR; ROS: Reactive oxygen species; rpm: Rounds per minute; RT: Room temperature; TAC: Total anthocyanin contents; TFC: Total flavonoid content; TPC: Total phenolics contents; UGTs: UDP glycosyl-transferase; $\mu \mathrm{g}$ : microgram

\section{Acknowledgements}

Not applicable.

\section{Authors' contributions}

MJR planned and designed the research; YX produced plant material; MJR performed the experiments, MJR and TX, YH collected and analyzed the data; MJR, XD, QX interpreted the results, MJR wrote the manuscript, QX and YX revised the manuscript. All authors have read and approved the final manuscript.

\section{Authors' information}

MJR, ORCID ID: 0000-0003-4911-9451.

\section{Funding}

This project was supported by the National Key Research and Development Program of China (2018YFD1000101), the National Natural Science

Foundation of China (31872052 and 31572105) and the Science and 
Technology Major Project of Guangxi (Gui Ke AA18118046). The funders have no role in the study design, data analysis and interpretation, and manuscript writing, but just provide the financial.

\section{Availability of data and materials}

All data generated or analyzed during this study are included in this published article [and its supplementary information files].

\section{Ethics approval and consent to participate}

Not applicable.

\section{Consent for publication}

Not applicable.

\section{Competing interests}

The authors declare that they have no competing interests.

Received: 19 September 2019 Accepted: 19 December 2019 Published online: 30 December 2019

\section{References}

1. Tripoli E, La Guardia M, Giammanco S, Di Majo D, Giammanco M. Citrus flavonoids: molecular structure, biological activity and nutritional properties: a review. Food Chem. 2007;104:466-79.

2. Huang $D$, Wang $X$, Tang $Z$, Yuan $Y, X u Y$, , He J, et al. Subfunctionalization of the Ruby2-Ruby1 gene cluster during the domestication of citrus. Nat Plants. 2018;4:930-41. https://doi.org/10.1038/s41477-018-0287-6.

3. Andersen OM, Markham KR. Flavonoids: chemistry, biochemistry and applications. Boca Raton: Taylor \& Francis: CRC Press; 2005.

4. Kaur H, Heinzel N, Schöttner M, Baldwin IT, Gális I. R2R3-NaMYB8 regulates the accumulation of phenylpropanoid-polyamine conjugates, which are essential for local and systemic defense against insect herbivores in Nicotiana attenuata. Plant Physiol. 2010;152:1731-47.

5. Luo J, Butelli E, Jones J, Tomlinson L, Martin CR. Methods and compositions for modifying plant flavonoid composition and disease resistance. 2009; http://europepmc.org/patents/PAT/WO2009103960. Accessed 27 Aug 2009.

6. Butelli E, Titta L, Giorgio M, Mock H-P, Matros A, Peterek S, et al. Enrichment of tomato fruit with health-promoting anthocyanins by expression of select transcription factors. Nat Biotechnol. 2008;26:1301-8.

7. Liu Y, Heying E, Tanumihardjo SA. History, global distribution, and nutritional importance of citrus fruits. Compr Rev Food Sci Food Saf. 2012;11:530-45.

8. Santos-buelga C, Scalbert A. Review proanthocyanidins and tannin-like compounds - nature, occurrence, dietary intake and effects on nutrition and health. J Sci Food Agric. 2000;80:1094-117.

9. Dixon R, Xie D, Sharma S. Proanthocyanidins a final frontier in flavonoid research? New Phytol. 2005;165:9-28.

10. Scalbert A, Johnson IT, Saltmarsh M. Polyphenols: antioxidants and beyond 1-3. Am J Clin Nutr. 2005;81:215-7.

11. Amorini AM, Lazzarino G, Galvano F, Fazzina G, Tavazzi B, Galvano G. Cyanidin-3-O- $\beta$-glucopyranoside protects myocardium and erythrocytes from oxygen radical-mediated damages. Free Radic Res. 2003:37:453-60.

12. Winkel-Shirley B. Flavonoid biosynthesis. A colorful model for genetics, biochemistry, cell biology, and biotechnology. Plant Physiol. 2001;126:485-93.

13. Martinelli F, Reagan RL, Uratsu SL, Phu ML, Albrecht U, Zhao W, et al. Gene regulatory networks elucidating huanglongbing disease mechanisms. PLOS ONE. 2013;8:e74256.

14. Xu M, Li Y, Zheng Z, Dai Z, Tao Y, Deng X. Transcriptional analyses of mandarins seriously infected by 'Candidatus Liberibacter asiaticus'. PLoS One. 2015;10:e0133652.

15. Wang Y, Zhou L, Yu X, Stover E, Luo F, Duan Y. Transcriptome profiling of Huanglongbing (HLB) tolerant and susceptible citrus plants reveals the role of basal resistance in HLB tolerance. Front Plant Sci. 2016;7:933.

16. Aritua V, Achor D, Gmitter FG, Albrigo G, Wang N. Transcriptional and microscopic analyses of citrus stem and root responses to Candidatus Liberibacter asiaticus infection. PLoS One. 2013;8:e73742.

17. Agati G, Tattini M. Multiple functional roles of flavonoids in photoprotection. New Phytol. 2010;186:786-93.

18. Kolb CA, Käser MA, Kopecký J, Zotz G, Riederer M, Pfündel EE. Effects of natural intensities of visible and ultraviolet radiation on epidermal ultraviolet screening and photosynthesis in grape leaves. Plant Physiol. 2001;127:863-75.

19. Rao MJ, Ding F, Wang N, Deng X, Xu Q. Metabolic mechanisms of host species against citrus Huanglongbing (Greening Disease). Crit Rev Plant Sci. 2019;0:1-16.
20. Mafra V, Kubo KS, Alves-Ferreira M, Ribeiro-Alves M, Stuart RM, Boava LP, et al. Reference genes for accurate transcript normalization in citrus genotypes under different experimental conditions. PLoS One. 2012;7:e31263.

21. Fan J, Chen C, Yu Q, Khalaf A, Achor DS, Brlansky RH, et al. Comparative transcriptional and anatomical analyses of tolerant rough lemon and susceptible sweet orange in response to 'Candidatus Liberibacter asiaticus' infection. Mol Plant-Microbe Interact. 2012;25:1396-407.

22. Chhikara N, Kour R, Jaglan S, Gupta P, Gat Y, Panghal A. Citrus medica: nutritional, phytochemical composition and health benefits-a review. Food Funct. 2018;9:1978-92.

23. Agati G, Stefano G, Biricolti S, Tattini M. Mesophyll distribution of 'antioxidant'flavonoid glycosides in Ligustrum vulgare leaves under contrasting sunlight irradiance. Ann Bot. 2009;104:853-61.

24. Tanaka T. Fundamental discussion of citrus classification. Stud Citrol. 1977;14:1-6.

25. Li Y, Baldauf S, Lim EK, Bowles DJ. Phylogenetic analysis of the UDP-glycosyltransferase multigene family of Arabidopsis thaliana. J Biol Chem. 2001;276:4338-43.

26. Douglas Grubb C, Zipp BJ, Ludwig-Müller J, Masuno MN, Molinski TF, Abel S. Arabidopsis glucosyltransferase UGT74B1 functions in glucosinolate biosynthesis and auxin homeostasis. Plant J. 2004;40:893-908.

27. Offen W, Martinez-fleites C, Yang M, Kiat-lim E, Davis BG, Tarling CA, et al. Structure of a flavonoid glucosyltransferase reveals the basis for plant natural product modification. EMBO J. 2006;25:1396-405

28. Li J, Liu X, Gao Y, Zong G, Wang D, Liu M, et al. Phytochemistry identification of a UDP-Glucosyltransferase favouring substrate- and regio- specific biosynthesis of flavonoid glucosides in Cyclocarya paliurus. Phytochemistry. 2019;163:75-88.

29. Tohge T, Nishiyama Y, Hirai MY, Yano M, Nakajima J, Awazuhara M, et al. Functional genomics by integrated analysis of metabolome and transcriptome of Arabidopsis plants over-expressing an MYB transcription factor. Plant J. 2005;42:218-35.

30. Fukuchi-mizutani M, Okuhara H, Fukui Y, Nakao M, Katsumoto Y, Yonekurasakakibara K, et al. Biochemical and molecular characterization of a novel UDP-Glucose: Anthocyanin 3'-O-Glucosyltransferase, a key enzyme for blue anthocyanin biosynthesis, from gentian. Plant Physiol. 2003;132:1652-63.

31. Jones P, Messner B, Nakajima J-I, Schäffner AR, Saito K. UGT73C6 and UGT78D1, glycosyltransferases involved in flavonol glycoside biosynthesis in Arabidopsis thaliana. J Biol Chem. 2003;278:43910-8.

32. Zandalinas SI, Sales C, Beltrán J, Gómez-Cadenas A, Arbona V. Activation of secondary metabolism in citrus plants is associated to sensitivity to combined drought and high temperatures. Front Plant Sci. 2017;7:1954.

33. Liu X, Lin C, Ma X, Tan Y, Wang J, Zeng M. Functional characterization of a flavonoid glycosyltransferase in sweet orange (Citrus sinensis). Front Plant Sci. 2018;9:1-14.

34. Kita M, Hirata Y, Moriguchi T, Endo-inagaki T, Matsumoto R, Hasegawa S, et al. Molecular cloning and characterization of a novel gene encoding limonoid UDP-glucosyltransferase in Citrus. FEBS Press. 2000;469:173-8.

35. Daniel JJ, Owens DK, McIntosh CA. Secondary product glucosyltransferase and putative glucosyltransferase expression during Citrus paradisi ( $\mathrm{CV}$ Duncan) growth and development. Phytochemistry. 2011;72:1732-8.

36. Ito T, Fujimoto S, Suito F, Shimosaka M, Taguchi G. C-Glycosyltransferases catalyzing the formation of di-C-glucosyl flavonoids in citrus plants. Plant J. 2017;91:187-98.

37. Huang D, Tang Z, Fu J, Yuan Y, Deng X, Xu Q. CsMYB3 and CsRuby1 form an 'activator-and-repressor'loop for regulation of anthocyanin biosynthesis in citrus. Plant Cell Physiol. 2019;198:1-13. https://doi.org/10.1093/pcp/pcz198

38. Wang S, Yang C, Tu H, Zhou J, Liu X, Cheng Y, et al. Characterization and metabolic diversity of flavonoids in citrus species. Sci Rep. 2017;7:1-10.

39. Xuan $L$, Wang $Z$, Jiang $L$. Vanillin assay of Arabidopsis seeds for proanthocyanidins. Bio-protocol. 2014;4:e1309.

40. Butler LG, Price ML, Brotherton JE. Vanillin assay for proanthocyanidins (condensed tannins): modification of the solvent for estimation of the degree of polymerization. J Agric Food Chem. 1982;30:1087-9.

41. Deshpande SS, Cheryan M, Salunkhe DK, Luh BS. Tannin analysis of food products. Crit Rev Food Sci Nutr. 1986;24:401-49.

42. Gonzalez A, Brown M, Hatlestad G, Akhavan N, Smith T, Hembd A, et al. TTG2 controls the developmental regulation of seed coat tannins in Arabidopsis by regulating vacuolar transport steps in the proanthocyanidin pathway. Dev Biol. 2016;419:54-63.

43. Debeaujon I, Nesi N, Perez P, Devic M, Grandjean O, Caboche M, et al. Proanthocyanidin-accumulating cells in Arabidopsis testa: regulation of differentiation and role in seed development. Plant Cell. 2003;15:2514-31.

44. Routaboul J-M, Dubos C, Beck G, Marquis C, Bidzinski P, Loudet O, et al. Metabolite profiling and quantitative genetics of natural variation for flavonoids in Arabidopsis. J Exp Bot. 2012;63:3749-64.

45. Trojak M, Skowron E. Role of anthocyanins in high-light stress response. World Sci News. 2017;81:150-68. 
46. Hussain S, Khalid MF, Saqib M, Ahmad S, Zafar W, Rao MJ, et al. Drought tolerance in citrus rootstocks is associated with better antioxidant defense mechanism. Acta Physiol Plant. 2018:40:135.

47. Veal EA, Day AM, Morgan BA. Hydrogen peroxide sensing and signaling. Mol Cell. 2007;26:1-14

48. Kuźniak $E$, Urbanek $H$. The involvement of hydrogen peroxide in plant responses to stresses. Acta Physiol Plant. 2000;22:195-203.

49. Zaare-Nahandi F, Hosseinkhani S, Zamani Z, Asadi-Abkenar A, Omidbaigi R. Delay expression of limonoid UDP-glucosyltransferase makes delayed bitterness in citrus. Biochem Biophys Res Commun. 2008;371:59-62.

50. Han S-I, Lee J, Kim MS, Chung SJ, Kim J-H. Molecular cloning and characterization of a flavonoid glucosyltransferase from Byungkyool (Citrus platymamma hort. ex Tanaka). Appl Biol Chem. 2017;60:49-55.

51. Huang $Y$, Si $Y$, Dane F. Impact of grafting on cold responsive gene expression in Satsuma mandarin (Citrus unshiu). Euphytica. 2011;177:25-32.

52. Lichtenthaler HK, Burkart S. Photosynthesis and high light stress. Bulg J Plant Physiol. 1999:25:3-16.

53. Hasanuzzaman M, Hossain MA, da Silva JAT, Fujita M. Plant response and tolerance to abiotic oxidative stress: antioxidant defense is a key factor. Crop Stress Manage Perspect Strateg. 2012:261-315 Springer.

54. Close DC, Mcarthur C. Rethinking the role of many plant phenolics protection from photodamage not herbivores? OIKOS. 2002;1:166-72.

55. Karimi M, Inzé D, Depicker A. GATEWAYTM vectors for Agrobacteriummediated plant transformation. Trends Plant Sci. 2002;7:193-5.

56. Clough SJ, Bent AF. Floral dip: a simplified method for Agrobacteriummediated transformation of Arabidopsis thaliana. Plant J. 1998;16:735-43.

57. Kasajima I, Ide Y, Ohkama-Ohtsu N, Hayashi H, Yoneyama T, Fujiwara T. A protocol for rapid DNA extraction from Arabidopsis thaliana for PCR analysis. Plant Mol Biol Report. 2004;22:49-52.

58. Edwards K, Johnstone C, Thompson C. A simple and rapid method for the preparation of plant genomic DNA for PCR analysis. Nucleic Acids Res. 1991;19:1349.

59. Livak K, Schmittgen TD. Analysis of relative gene expression data using realtime quantitative $P C R$ and the $2-\Delta \Delta C T$ method. Methods. 2001;25:402-8.

60. Wang Z, Chen M, Chen T, Xuan L, Li Z, Du X, et al. TRANSPARENT TESTA 2 regulates embryonic fatty acid biosynthesis by targeting FUSCA 3 during the early developmental stage of Arabidopsis seeds. Plant J. 2014;77:757-69.

61. Broadhurst RB, Jones WT. Analysis of condensed tannins using acidified vanillin. J Sci Food Agric. 1978;29:788-94.

62. Sumanta N, Haque Cl, Nishika J, Suprakash R. Spectrophotometric analysis of chlorophylls and carotenoids from commonly grown fem species by using various extracting solvents spectrophotometric analysis of chlorophylls and carotenoids from commonly grown fern species by using various extracting solvents. Res J Chem Sci. 2014;4:63-9.

63. Velioglu YS, Mazza G, Gao L, Oomah BD. Antioxidant activity and total phenolics in selected fruits, vegetables, and grain products. J Agric Food Chem. 1998:46:4113-7.

64. Dewanto V, Wu X, Adom KK, Liu RH. Thermal processing enhances the nutritional value of tomatoes by increasing total antioxidant activity. J Agric Food Chem. 2002;50:3010-4.

65. Nakata M, Mitsuda N, Herde M, Koo AJK, Moreno JE, Suzuki K, et al. A bHLHtype transcription factor, ABA-inducible bHLH-type transcription factor/JAassociated MYC2-LIKE1, acts as a repressor to negatively regulate jasmonate signaling in Arabidopsis. Plant Cell. 2013:25:1641-56.

66. Nakata M, Ohme-Takagi M. Quantification of anthocyanin content. Bioprotocol. 2014:4:e1098

67. Özgen M, Scheerens JC, Reese RN, Miller RA. Total phenolic, anthocyanin contents and antioxidant capacity of selected elderberry (Sambucus canadensis L.) accessions. Pharmacogn Mag. 2010;6:198.

68. Velikova V, Yordanov I, Edreva A. Oxidative stress and some antioxidant systems in acid rain-treated bean plants: protective role of exogenous polyamines. Plant Sci. 2000;151:59-66.

69. Feng Y, Zhang M, Guo Q, Wang G, Gong J, Xu Y, et al. Manipulation of mono-ubiquitin improves chilling tolerance in transgenic tobacco (Nicotiana tabacum). Plant Physiol Biochem. 2014;75:138-44.

\section{Publisher's Note}

Springer Nature remains neutral with regard to jurisdictional claims in published maps and institutional affiliations.

\section{Ready to submit your research? Choose BMC and benefit from:}

- fast, convenient online submission

- thorough peer review by experienced researchers in your field

- rapid publication on acceptance

- support for research data, including large and complex data types

- gold Open Access which fosters wider collaboration and increased citations

- maximum visibility for your research: over $100 \mathrm{M}$ website views per year

At $\mathrm{BMC}$, research is always in progress.

Learn more biomedcentral.com/submissions 